\title{
Identification of validated substitute for Asoka (Saraca asoca (Roxb.) Willd.) by phytochemical and pharmacological evaluations
}

\author{
Sulaiman C. T., Jyothi C. K., Jinu Krishnan Unnithan G., Prabhukumar K.M. and Indira Balachandran
}

\begin{abstract}
Background: Asoka is an important drug used in many Ayurvedic formulations. The bark of Saraca asoca (Roxb.) Willd. is the genuine source plant for Asoka. Due to diminishing availability and increasing requirement, the Ayurvedic industry is facing acute shortage of this crude drug. It is usual that traders try to deceive the consumers by tendering similar bark of other trees. The unscientific substitution may affect the quality of herbal preparations adversely. The aim of the present study is to identify a scientifically validated substitute for Asoka.

Results: Phytochemical and pharmacological evaluation has been carried out using plant parts of four medicinal plants viz, Saraca asoca (AB), Polyalthia longifolia (PB), Shorea robusta (SB), and Trema orientalis (TB). The results of the study showed that among the tested extracts, $A B$ and SB showed significant dose-dependent protection against bilateral ovariectomy-induced changes in estrus cycle, uterus weights, and lipid profile. LC/MS analysis revealed the presence of active catechins in both AB and SB. Polyalthia longifolia, the common adulterant of Asoka, showed entirely different chemical and biological properties.
\end{abstract}

Conclusion: This study concluded the possibility of using S. robusta bark as substitute for Asoka.

Keywords: Asoka, HPTLC, HPLC, LC/MS, Estrogenic activity

\section{Background}

In Ayurveda, Asoka is used for the treatment of excessive uterine bleeding, gynecological problems, stomach ache, leucorrhoea, menstrual irregularities, internal piles, diabetes, dyspepsia, indigestion, burning sensation, blood disorders, fractures, tumors, bites, ulcerations, skin discoloration, etc. [1]. The bark of Saraca asoca (Roxb.) Willd. (Leguminosae) is the genuine source plant for Asoka. It is found throughout India, especially in Himalaya, Kerala, Bengal, and the whole south region [2].

Ayurvedic texts describe more than 50 preparations of Asoka for the treatment of a variety of ailments in which stem bark of $S$. asoca is used as one of the main

* Correspondence: sulaimanct@aryavaidyasala.com

Phytochemistry Division, Centre for Medicinal Plants Research, Arya Vaidya Sala, Kottakkal, Malappuram, Kerala 676503, India ingredients. The bark is also useful in treating scorpionsting and internal piles [3].

The well-known Ayurvedic medicines "Ashokarishta" and "Ashokaghrita" are prepared with S. asoca bark as the primary raw material. A difficulty in the commercial cultivation of $S$. asoca is its inherent slow growth rate and poor yield of bark. Due to dwindling availability and increasing requirement, the Ayurvedic industry is facing acute shortage of this crude drug. The original material has become scarce and the market item is often admixed with bark of other trees which pass off as Asoka bark. It is usual that traders try to deceive the consumers by tendering similar bark of other trees. Since these unauthentic materials do not possess the pharmacological effects of Asoka, the drugs prepared using them are liable to be non-effective, if not harmful. The most widely used
Springer Open
(C) The Author(s). 2020 Open Access This article is licensed under a Creative Commons Attribution 4.0 International License, which permits use, sharing, adaptation, distribution and reproduction in any medium or format, as long as you give appropriate credit to the original author(s) and the source, provide a link to the Creative Commons licence, and indicate if changes were made. The images or other third party material in this article are included in the article's Creative Commons licence, unless indicated otherwise in a credit line to the material. If material is not included in the article's Creative Commons licence and your intended use is not permitted by statutory regulation or exceeds the permitted use, you will need to obtain permission directly from the copyright holder. To view a copy of this licence, visit http://creativecommons.org/licenses/by/4.0/. 
adulterant is the bark of Polyalthia longifolia which is known as "False Asoka" $[4,5]$.

The aim of the present study was to find out a substitute for bark of S. asoca by evaluating the phytochemistry and pharmacology of its stem and root of other species such as Polyalthia longifolia, Shorea robusta, and Trema orientalis.

\section{Methods}

\section{Chemicals and reagents}

Folin-Ciocalteu reagent was procured from Sisco Research Laboratory (SRL), Mumbai, India. LC/MS grade solvents and analytical standards such as gallic acid and quercetin were procured from Sigma Chemicals Co. (Bangalore, India). All other chemicals employed were of standard analytical grade from Merck India.

\section{Collection of plant materials}

Plants such as $S$. asoca, $P$. longifolia and $T$. orientalis were collected from Herb garden of the Centre. The bark of S. robusta was collected from Chhattisgarh. All the materials were authenticated by Plant Systematics and Genetic Resources division of the Centre, and herbarium specimens were deposited in CMPR Herbarium (CMPR 11252, CMPR 11253, CMPR 11251, and CMPR 11255)

\section{Extraction of materials}

The plant materials were shade dried and pulverized. Five grams each of the sample was successively extracted with various solvents like $n$-hexane, chloroform, and methanol by refluxing for $6 \mathrm{~h}$. Crude extracts were prepared separately with methanol, water, and hydroalcohol (ethanol:water 50:50) using reflux extraction method. The process was repeated in triplicates. The final extracts were pooled and concentrated at $40^{\circ} \mathrm{C}$ using a Rotary evaporator (Heidolph, Germany) and it was made up to $100 \mathrm{ml}$ with respective solvents in standard flasks. The extracts were kept under refrigeration for various phytochemical analyses.

\section{Estimation of total polyphenolics}

The total phenolic content (TPC) was determined using Folin-Ciocalteu reagent $[6,7]$. TPC was expressed as gallic acid equivalents (GAE) in $\mathrm{mg} / \mathrm{g}$ of the sample.

\section{Estimation of total catechins}

Catechins and other flavonoids were isolated by overnight shaking at $70^{\circ} \mathrm{C}$ in incubator shaker. Twenty grams of powdered materials was macerated with $200 \mathrm{ml}$ of methanol and kept for overnight shaking at $250 \mathrm{rpm}$. The residue was concentrated to dryness under reduced pressure in rotary evaporator (Heidolph, Germany) and it was redissolved in LC/MS grade methanol.
Estimation of total catechins was carried out using diazotized sulfanilamide as reported previously [8]. The absorbance of the samples and standards was measured at $425 \mathrm{~nm}$ using spectrophotometer (Shimadzu, Japan) against reagent blank. The concentration of catechins in the sample extract was estimated from standard curve of catechin.

\section{High-performance thin-layer chromatographic (HPTLC) analysis}

HPTLC analysis was performed using CAMAG HPTLC system (Switzerland). Samples were applied using automatic sample applicator, CAMAG ATS- 4 on aluminumbacked pre-coated silica gel $60 \mathrm{~F}_{254}$ TLC plate (Merck, India). Mobile phase was standardized as toluene, ethyl acetate in the ratio of 8:2. The chromatogram was developed in a saturated Twin Trough chromatographic chamber (Camag, Switzerland). The developed plate was visualized under UV at $254 \mathrm{~nm}$ and $366 \mathrm{~nm}$ and in visible light after derivatizing with anisaldehyde-sulphuric acid reagent followed by heating at $105^{\circ} \mathrm{C}$ for $5 \mathrm{~min}$.

\section{High-performance liquid chromatography (HPLC) analysis} Comparative HPLC profiling was done using Shimadzu High-Performance Liquid Chromatographic system equipped with LC-10ATVP pump, SPD M10AVP Photo Diode Array Detector in combination with CLASS-VP 6.12 SP5 integration software. The mobile phase used for the separation was HPLC grade methanol (A) and $0.1 \%$ formic acid in water $(\mathrm{B})$ in a gradient elution, with $\% \mathrm{~B}$ at $0.01-65,5-50,8-40,12-30,15-20,18-10,23-$ $30,25-40,28-50$, and 30-60. The column used was Merck HIBAR Lichrospher RP $18 \mathrm{e}(5 \mu \mathrm{m})$ with a Phenomenex guard column $(4 \mathrm{~mm} \times 2 \mathrm{~mm}$ i.d, $5 \mu \mathrm{m})$. The samples were injected using a 20- $\mu$ l loop (Rheodyne Rohnet Park, CA, USA). The flow rate was maintained at $0.8 \mathrm{ml} / \mathrm{min}$. The PDA signal was recorded at $360 \mathrm{~nm}$.

\section{LC/MS characterization of catechin fractions}

LC-ESI/MS analysis of catechin fraction was conducted on Agilent 6520 accurate mass Q-TOF LC/MS coupled with Agilent LC 1200 equipped with Extend-C18 column of $1.8 \mu \mathrm{m}, 2.1 \times 50 \mathrm{~mm}$. Gradient elution was performed with LC/MS grade acetonitrile (A) and 0.1\% acetic acid in methanol (B) at a constant flow rate of 0.7 $\mathrm{ml} / \mathrm{min}$, with an increase in the volume of B \%: $5-20 \%$, $12-30 \%, 19-40 \%, 26-50 \%$, and $30-40 \%$. The MS analysis was performed using ESI in negative mode with the following conditions: drying gas (nitrogen) flow $5 \mathrm{~L} / \mathrm{min}$, nebulizer pressure $40 \mathrm{psig}$, drying gas temperature $325^{\circ} \mathrm{C}$, capillary voltage $+3000 \mathrm{~V}$, fragmentor volt $125 \mathrm{~V}$, and Oct RF Vpp $750 \mathrm{~V}$. The mass fragmentation was performed with varying collision energy $4 \mathrm{~V} / 100$ DA with an offset of $8 \mathrm{~V}$. 


\section{Acute oral toxicity studies of plant extracts}

Two hundred and fifty grams of various samples such as $S$. asoca bark, S. asoca stem, P. longifolia bark, S. robusta bark, and $T$. orientalis bark were extracted with water using soxhlet extraction method for $72 \mathrm{~h}$. The final extracts were concentrated to dryness under reduced pressure using rotary evaporator (Heidolph, Germany).

The experiment was conducted on Wistar rats (females) weighing 147 to $204 \mathrm{~g}$ and aged 8 to 9 weeks obtained from the Animal House, J.S.S. College of Pharmacy, Ootacamund, Tamil Nadu, India. The rats were distributed into 5 groups with 6 animals in each group. The experimental procedures relating to the animals were authorized by the Committee for the Purpose of Control and Supervision of Experiments on Animals (CPCSEA) (approval no. JSSCP/IAEC/OT/Ph.D/Ph.Cology/06/201718) before starting the study and were conducted under the internationally accepted principles for laboratory animal use and care [9].

The extracts were prepared from a plant material having a high safety margin, and hence it was decided to use $2000 \mathrm{mg} / \mathrm{kg}$ (limit test) for this study. The test item was prepared immediately prior to administration on respective treatment days. A quantity of $2 \mathrm{~g}$ of the test item was dissolved in distilled water and the volume was made up to $10 \mathrm{ml}$ to get a test item concentration of $200 \mathrm{mg} / \mathrm{ml}$. Homogeneity of the test item in the vehicle was maintained during treatment by constant stirring and mixing. The test substance was administered soon after preparation.

The prepared test item solutions were administered once orally as gavage to the fasted (16-18 $\mathrm{h}$ ) rats at the dose volume of $10 \mathrm{ml} / \mathrm{kg}$ b.wt. to deliver a dose of 2000 $\mathrm{mg} / \mathrm{kg}$ b.wt. Food was offered about 3-4 h after dosing. Water was not withheld.

The treated rats were observed five times during day 1 (day of administration) i.e., at $30 \mathrm{~min}$ and four times hourly (post-administration) intervals and once daily, and thereafter for a total of 14 days. The clinical signs were recorded on all working days. The body weights of rats were recorded on test day 1 (pre-administration), day 8 (7 days post-administration), and day 15 (14 days post-administration). The rats were euthanized by using diethyl ether anesthesia and necropsied.

\section{Evaluation of estrogenic activity}

The samples, Saraca asoca bark (AB), Saraca asoca stem (AS), Polyalthia longifolia bark (PB), Shorea robusta bark (SB), and Trema orientalis bark (TB), were studied for their estrogenic activity in ovariectomized Wistar rats [10].

The experiment was conducted on 72 numbers of Wistar rats (females) weighing 64 to $99 \mathrm{~g}$ and aged 4 weeks obtained from the Animal House, J.S.S. College of Pharmacy, Ootacamund, Tamil Nadu, India . The rats were distributed into 5 groups with 6 animals in each group. The experimental procedures relating to the animals were authorized by the Committee for the Purpose of Control and Supervision of Experiments on Animals (CPCSEA) (JSSCP/IAEC/ OT/Ph.D/Ph.Cology/05/2017-18) before starting the study and were conducted under the internationally accepted principles for laboratory animal use and care.

Animals were divided into 12 groups of 6 each.

I. Groups 1 and 2 served as sham and control, respectively, and received distilled water (10 ml $/ \mathrm{kg}$., p.o.).

II. Groups 3 and 4 received $\mathrm{AB}$ extract at a dose of 200 and $400 \mathrm{mg} / \mathrm{kg}$, p.o., respectively.

III. Groups 5 and 6 received AS extract at a dose of 200 and $400 \mathrm{mg} / \mathrm{kg}$., p.o., respectively.

IV. Groups 7 and 8 received PB extract at a dose of 200 and $400 \mathrm{mg} / \mathrm{kg}$., p.o., respectively.

V. Groups 9 and 10 received SB extract at a dose of 200 and $400 \mathrm{mg} / \mathrm{kg}$., p.o., respectively.

VI. Groups 11 and 12 received TB extract at a dose of 200 and $400 \mathrm{mg} / \mathrm{kg}$., p.o., respectively.

Bilateral ovariectomy was performed in all the groups, except sham group via dorsolateral approach under general anesthesia. In sham group animals, only placebo surgery was performed. After 1 week of recovery, animals were given respective treatments for a period of 8 weeks. The estrogenic activity of the test items was assessed by analyzing the estrus cycle, uterine weight, uterine glycogen content, serum lipid profile, and histopathology of the uterus.

\section{Estimation of uterine glycogen content}

Uterine tissue (15 mg) was homogenized in $20 \mathrm{ml} 30 \%$ $\mathrm{KOH}$, and heated at $100^{\circ} \mathrm{C}$ for $30 \mathrm{~min}$, to inactivate enzymes and destroy free glucose. To isolate glycogen, samples was diluted with $1.2 \mathrm{vol} 95 \%$ ethanol, frozen at $-80^{\circ} \mathrm{C}$ for $60 \mathrm{~min}$, then thawed and centrifuged at $9600 \times g$ for $10 \mathrm{~min}$. The supernatant was discarded and the pellets dried overnight. To breakdown glycogen to glucose, $100 \mu \mathrm{l} 1.0 \mathrm{~N} \mathrm{HCl}$ was added to each tube and heated at $90-100{ }^{\circ} \mathrm{C}$ for $2.5 \mathrm{~h}$. Glucose concentrations was measured by using Glucose Assay Kit (120235, M/s. Erba Mannheim, Transasia Biomedicals Ltd. Solan, HP, India). The percentage of glycogen is calculated using the standard formula.

\section{Estimation of lipid profile}

The blood sample collected was allowed to clot for 45 min at room temperature. The serum was separated by centrifugation at $3000 \mathrm{rpm}$ at $30^{\circ} \mathrm{C}$ for $15 \mathrm{~min}$ and used for assaying total cholesterol, triglycerides, HDL, and total protein using Precision Biomed assay kits. 


\section{Histopathological studies}

The uterus tissue was fixed in the $10 \%$ formalin, dehydrated in gradual ethanol (50-100\%), cleared in xylene, and embedded in paraffin wax. The sections, with $5-6 \mu \mathrm{m}$ thickness, were then prepared using rotary microtome and stained with hematoxylin and eosin dye for microscopic observation of histopathological changes in the uterus.

\section{Statistical analysis}

For determination of significant intergroup differences of each parameter, one-way analysis of variance (ANOVA) was carried out. Dunnett's test was used for individual comparisons after significant ANOVA results. The differences with $p<0.05$ were considered statistically significant. Graphpad Prism-6 software (Graphpad Software Inc., USA) was used for the statistical analysis.

\section{Results}

\section{Estimation of total catechins}

Total catechins were estimated using spectrophotometric method with diazotized sulfanilamide. The bark of $S$. asoca showed the highest catechin content (21.62) followed by $T$. orientalis (16.46). The catechin contents of other samples are much lower while comparing with the bark of $S$. asoca, which is the genuine drug.

\section{Estimation of total phenolic content (TPC)}

Total phenolic content (TPC) of selected species was estimated for different extracts such as methanol, water, and hydroalcohol. TPC was calculated from calibration curve of gallic acid $\left(R^{2}=0.992\right)$. TPC of various species are presented as Fig. 1. Highest TPC was showed by
T. orientalis for all the extracts. Hydroalcoholic extract of T. orientalis provided $113.11 \mathrm{mg}$ equivalent of phenolics. Phenolic contents of bark of S. asoca are 78.66, 47.77, and 102.11 for methanol, water, and hydroalcohol, respectively. Phenolic content of $S$. asoca stem is much lower than that of its bark.

\section{HPTLC profiling}

Thin-layer chromatography is a rapid and reliable technique for phytochemical comparison. HPTLC provides advancement such as spectral evaluation, digital documentation, and densitometry scanning for proper chemical comparison of various compounds separated with different chromospheres. Comparative HPTLC profiles were developed for various extracts like $n$-hexane and chloroform (Fig. 2). TLC profile of hexane extracts, at $366 \mathrm{~nm}$ a common band with $R_{\mathrm{f}} 0.48$ was observed in all the species. Compound at $R_{f} 0.08$ (blue) is common for $\mathrm{AB}, \mathrm{AS}$, and $\mathrm{PB}$. A blue band at 0.11 (blue) was found to be present in $\mathrm{AB}$ and AS. A band at 0.88 (blue) is present in Polyalthia bark only. At $254 \mathrm{~nm}$, a common band at $R_{\mathrm{f}}$ 0.54 is present in all the selected species. Bands at $R_{\mathrm{f}} 0.08$ and 0.12 were observed in $\mathrm{AB}, \mathrm{AS}, \mathrm{PB}$, and $\mathrm{TB}$. Common band at $R_{f} 0.24$ were found in $\mathrm{PB}$ and $\mathrm{SB}$. A common band at $R_{f} 0.39$ was noted in $P B$ and TB. A single band at $R_{f} 0.7$ is observed in $\mathrm{PB}$, a band at $\mathrm{R}_{\mathrm{f}} 0.78$ was observed in $\mathrm{SB}$ and $\mathrm{R}_{\mathrm{f}} 0.84$ in $\mathrm{PB}$.

Tracks: $A B, A S, P B, S B$, and $T B$

TLC profile of chloroform extracts at $366 \mathrm{~nm}$, common bands at $R_{\mathrm{f}} 0.47$ (fluorescent blue), 0.54 (red), and 0.87 (dark blue) were observed in all the species. Band at $R_{f}$

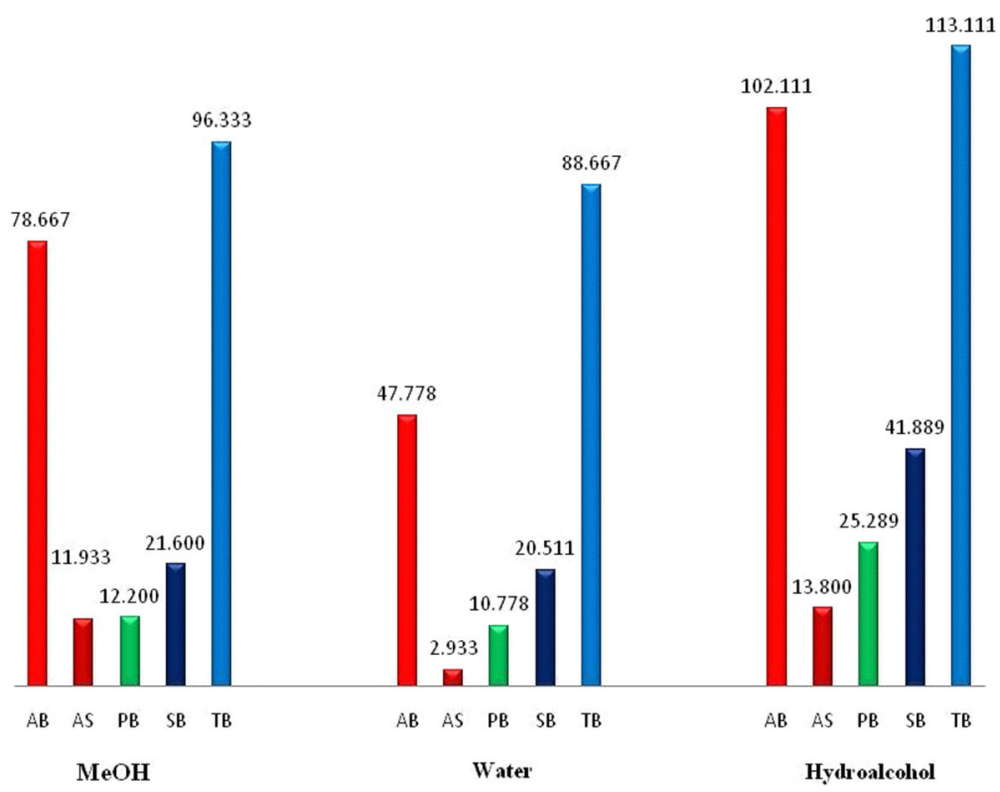

Fig. 1 Total phenolics of selected species 

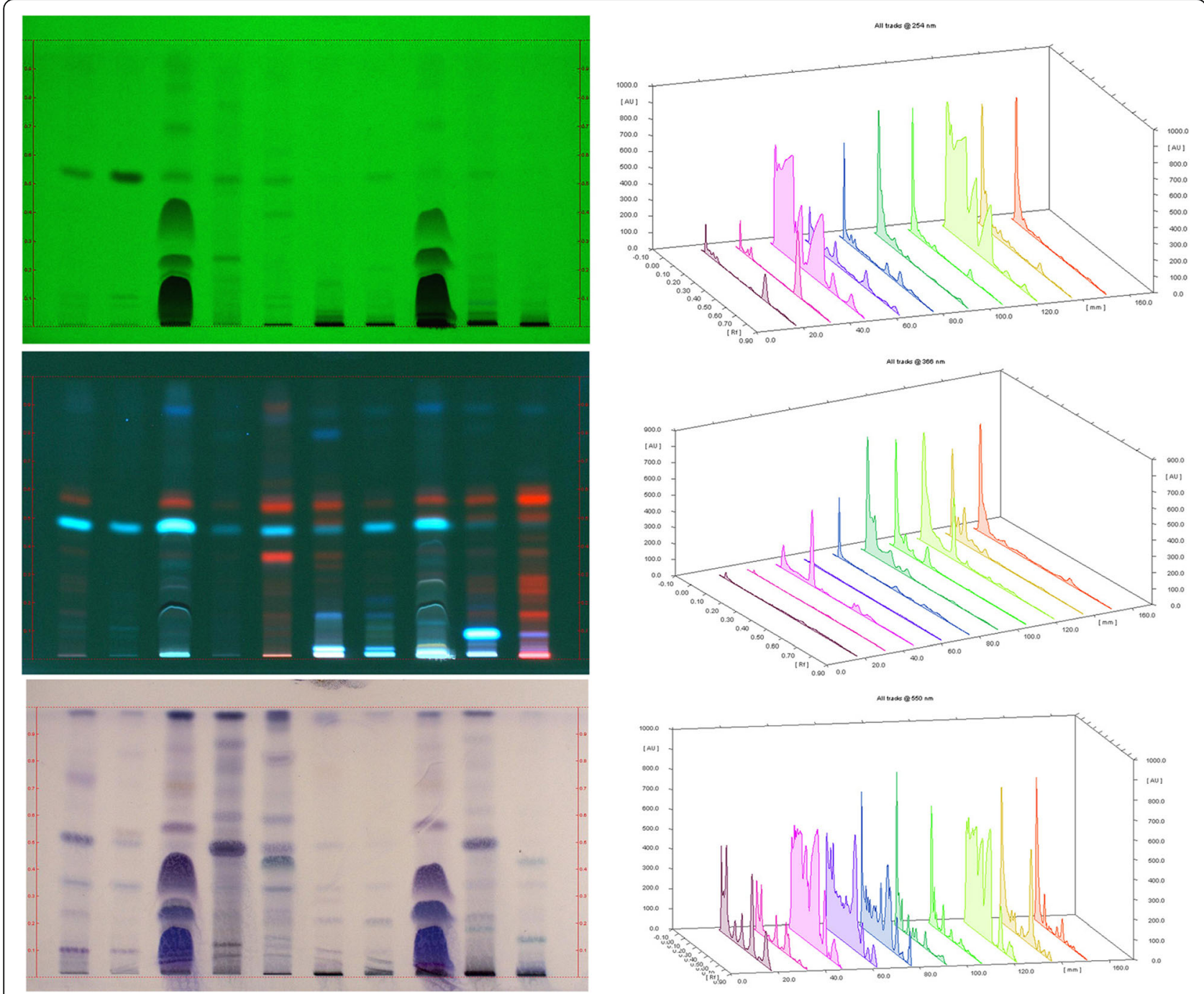

Fig. 2 HPTLC profiling of $n$-hexane and chloroform extracts of selected species, (1-5, n-hexane extracts; 6-10 Chloroform extracts)

0.04 (fluorescent blue) is common for three species $A B$, $\mathrm{AS}$, and PB. A band at 0.09 (fluorescent blue) was found in SB, 0.13 (blue) in $\mathrm{PB}$ and 0.15 (blue) in Asoka bark. At $254 \mathrm{~nm}$, a band at $R_{\mathrm{f}} 0.05$ is observed in $\mathrm{AB}, \mathrm{PB}$, and $\mathrm{SB}$. A common band at $\mathrm{R}_{\mathrm{f}} 0.54$ was observed in $A S, P B$, and $S B$. A band at $R_{f} 0.04$ was visible only in $A B$. Bands at $R_{f} 0.26,0.38$, and 0.7 were observed only in $\mathrm{PB}$.

\section{HPLC analysis}

HPLC profiling of bark extracts of four selected species along with stem extract of $S$. asoca was done using reverse phase chromatographic conditions. Retention time $\left(t_{\mathrm{R}}\right)$ was recorded at $360 \mathrm{~nm}$. Both the bark and stem of $S$. asoca showed some common peaks at $t_{\mathrm{R}} 3.6,16.1$, 18.1 and 19.9. Most of the similar compounds separated were confirmed by comparing the retention time and online UV spectra. Two major peaks with comparatively higher peak area percentage at 16.3 and 19.3 were observed for $S$. asoca stem. All the other species selected have less similarity when compared to the genuine source plant part (Fig. 3a, b).

HPLC analyses concluded that the different species selected are not comparable with the genuine drug in terms of phytochemicals separated. However, S. asoca bark showed a few similar phytochemicals with that of its stem.

\section{LC/MS analysis of catechin fractions}

The fractions were subjected to LC/MS analysis for detailed characterization. LC/MS analysis was done in ESI negative mode in order to obtain maximum ionization. Total ion chromatogram (TIC) obtained for MS analysis was extracted to Base Peak Chromatogram (BPC) and integrated to record all the molecular ion peaks. The molecular ions with different $[\mathrm{M}-\mathrm{H}]$ 


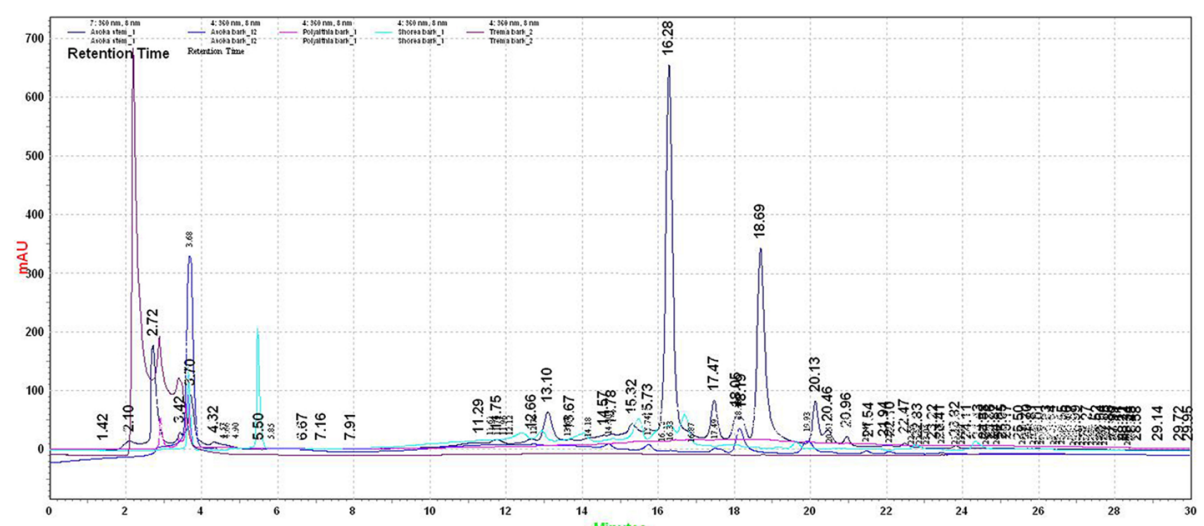

A. Overlaid chromatogram of selected barks

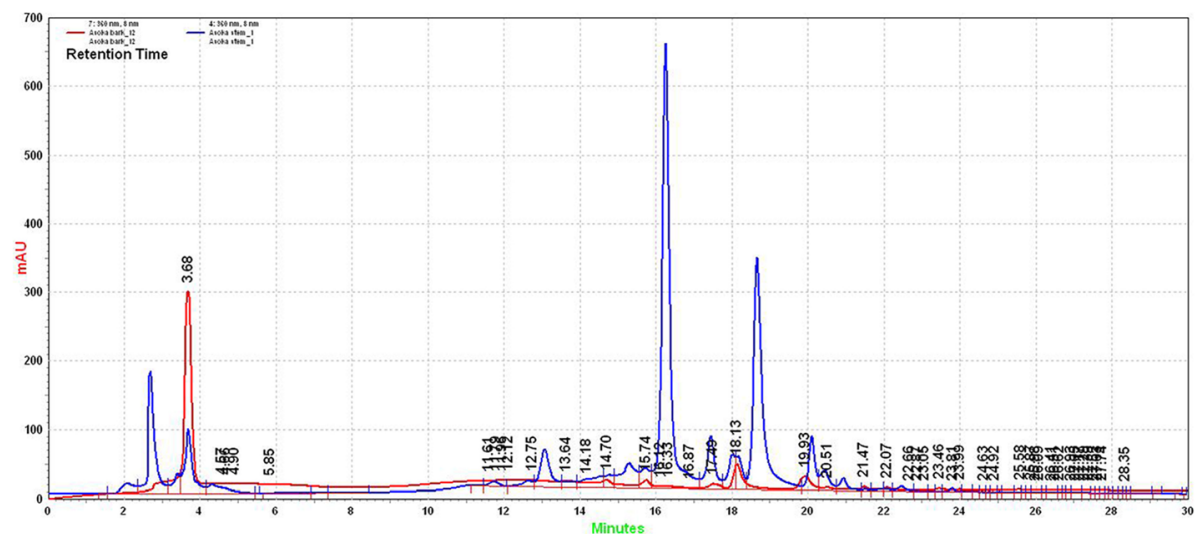

B Overlaid chromatogram of bark and stem of S. asoca

Fig. 3 HPLC chromatogram of selected species. a Overlaid chromatogram of selected barks. b Overlaid HPLC chromatogram of bark and stem of S. asoca

values were evaluated and further characterization was carried out by MS/MS analysis. On MS/MS analysis, molecular ions were fragmented on collision-induced dissociation (CID). The tentative structure was assigned based on MS/MS fragments obtained for each [M-H] value (Table 1, Fig. 4). Catechins such Catechin (C), Epicatechin (EC), Epicatechin-3 gallate (ECG), Gallo catechin (GC) and Gallocatechin-3-gallate (GCG) were identified from the bark of $S$. asoca and the bark of S. robusta. Catechin, Epicatechin, and gallo catechin were found in the stem of S. asoca and the bark of T. orientalis. Catechins were not identified in the bark of $P$. longifolia.

\section{Evaluation of acute oral toxicity}

The acute oral toxicity of various extracts such as $A B$, $\mathrm{AS}, \mathrm{SB}$, and TB were evaluated in Wistar rats. There were no toxic signs and pre-terminal deaths. All the rats gained weight through the observation period. At the end of the observation period, the rats were sacrificed using diethyl ether anesthesia and subjected to detailed necropsy and no abnormality was detected.

Based on the results of the acute oral toxicity (Acute Toxic Class Method) of the test extracts Wistar rats, the $\mathrm{LD}_{50}$ of the test item may be classified as GHS category $5(\mathrm{LD} 50>2000 \mathrm{mg} / \mathrm{kg}$ ) as per OECD

Table 1 LC-MS/MS analysis of catechin fraction of selected species

\begin{tabular}{|c|c|c|c|c|c|}
\hline Compound & Molecular formula & $\begin{array}{l}\mathrm{m} / \mathrm{z} \\
{[\mathrm{M}-\mathrm{H}]}\end{array}$ & MS/MS & Present in & Reference \\
\hline Catechin & $\mathrm{C}_{15} \mathrm{H}_{14} \mathrm{O}_{6}$ & 289.2902 & $248.30,203.08$ & $A B, A S, S B, T B$ & [11] \\
\hline Epicatechin & $\mathrm{C}_{15} \mathrm{H}_{14} \mathrm{O}_{6}$ & 289.2902 & $248.30,203.08,109.2$ & $A B, A S, S B, T B$ & [12] \\
\hline Epicatechin-3 gallate & $\mathrm{C}_{22} \mathrm{H}_{18} \mathrm{O}_{10}$ & 441.6401 & $289.28,169.14$ & $A B, S B$ & [13] \\
\hline Gallo catechin & $\mathrm{C}_{15} \mathrm{H}_{14} \mathrm{O}_{7}$ & 305.2614 & 289.28 & $A B, A S, S B, T B$ & {$[11,13]$} \\
\hline Gallocatechin-3-gallate & $\mathrm{C}_{22} \mathrm{H}_{18} \mathrm{O}_{11}$ & 457.7621 & $305.26,169.14$ & $A B, S B$ & {$[11,14]$} \\
\hline
\end{tabular}



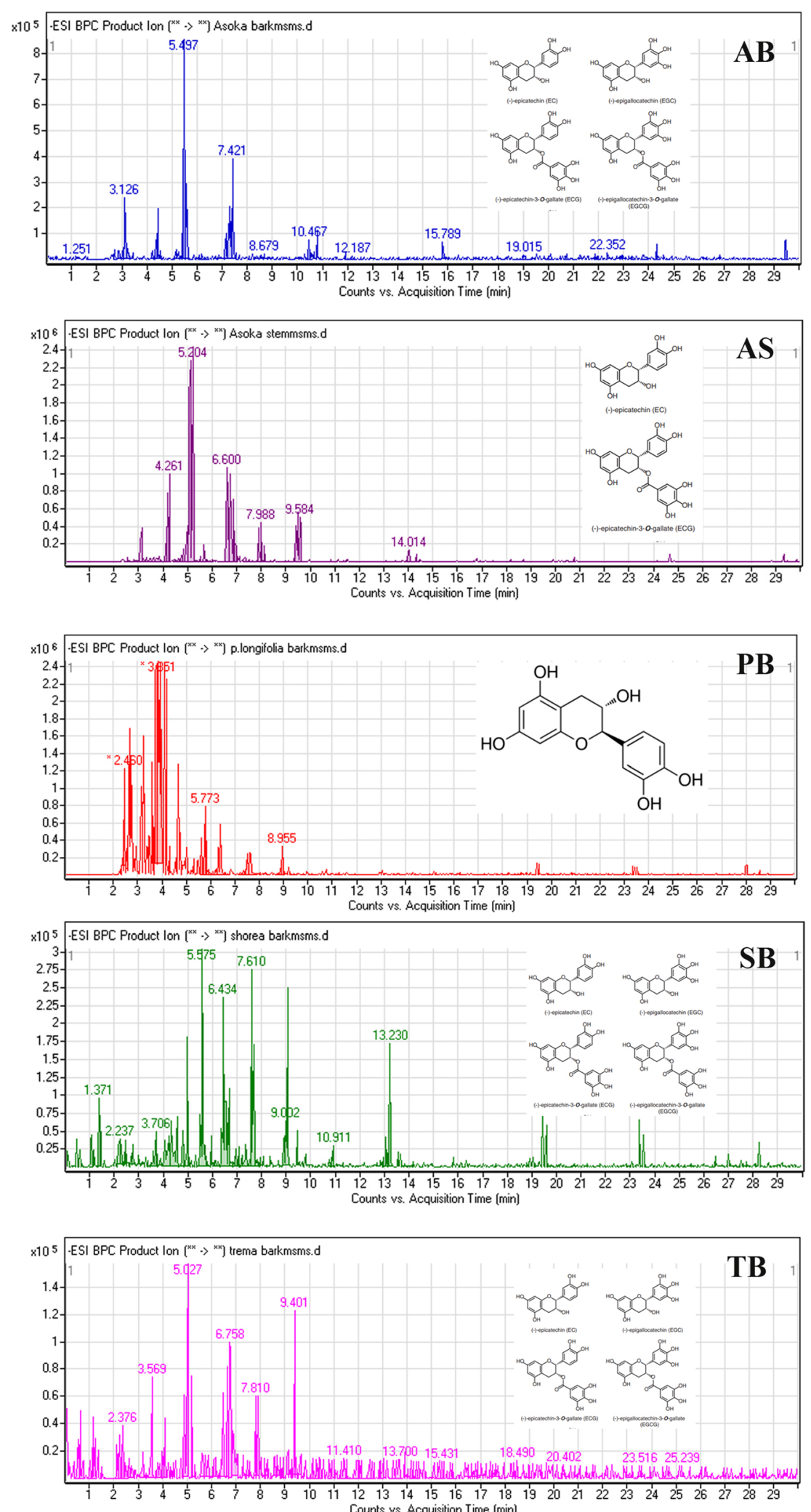

Fig. 4 LC-ESI-MS/MS analysis of Catechin fractions 
guideline no. 423, December 2001, and it is protective in nature [15].

\section{Evaluation of estrogenic activity}

The results of the study showed that bilateral ovariectomy has produced a significant decrease in uterine weight, uterine glycogen content, and epithelial thinning and endometrial atrophy of the uterus. In addition, a significant decrease in serum HDL levels and a significant increase in serum total cholesterol and triglyceride levels, which also had an acyclic effect on the estrus cycle, were observed in group 2, control animals when compared to group 1 , sham-operated animals $(p<0.05)$. Among the test item treated groups, groups 3 and 4 treated with $\mathrm{AB}$ extract and groups 9 and 10 treated with SB extract show a significant dose-dependent protection against bilateral ovariectomy-induced changes ( $p$ $<0.05)$. The results of the study, therefore, conclude that among the extracts tested, $\mathrm{AB}$ and $\mathrm{SB}$ extracts show significant estrogenic activity under the testing conditions and the model employed.

\section{Effect of test items on body weight}

No significant difference in the body weights was observed with the treated groups (Table 2) when compared to control group $(p>0.05)$.

\section{Effect of test items on uterine weight}

Bilateral ovariectomy produced a significant decrease in uterine weights (Table 3 ) in group 2 control when compared to group 1 sham $(p<0.05)$. Groups 3 and 4 treated with $\mathrm{AB}$ extract and groups 9 and 10 treated with SB extract show a significant dose-dependent protection against bilateral ovariectomy-induced changes in uterine weights $(p<0.05)$. In addition, Group 6 animals treated with high dose of AS extract also show a significant protection $(p<0.05)$.

\section{Effect of test items on uterine glycogen content}

Bilateral ovariectomy produced a significant decrease in uterine glycogen content (Table 3 ) in group 2 control when compared to group 1 sham $(p<0.05)$. Groups 3 and 4 treated with $\mathrm{AB}$ a non-significant protection against bilateral ovariectomy-induced changes in uterine glycogen content $(p>0.05)$. Other treated groups show no protection against the ovariectomy-induced changes in uterine glycogen content $(p>0.05)$.

\section{Effect of test items on serum lipid profile}

Bilateral ovariectomy produced a significant increase in serum total cholesterol and triglyceride levels and significantly decreased serum HDL levels in group 2 control when compared to group 1 sham ( $\mathrm{p}<0.05)$. Among the treated groups, only high doses of $\mathrm{AB}, \mathrm{AS}$, and $\mathrm{SB}$ extracts show significant protection against the ovariectomyinduced changes in serum lipid profile (Table 3).

\section{Effect of test items on estrus cycle}

Bilateral ovariectomy produced arrest of estrus cycle at diestrous phase in Group 2 control when compared to Group 1 sham. Groups 3 and 4 treated with $A B$ extract and groups 9 and 10 treated with SB extract significantly restore the acyclic effect of bilateral ovariectomy. Other treatment shows no or minimal effects against bilateral ovariectomy-induced acyclic effects.

\section{Effect of test items on histopathology of uterus}

Sham-operated animals (group 1) showed normal architecture of the uterus. Ovariectomized animals (group 2) showed severe degree of atrophy of uterus characterized by extensive areas of epithelial thinning and atrophy of endometrial glands. Groups 3 and 4 treated with $\mathrm{AB}$ extract and groups 9 and 10 treated with SB extract show a moderate degree of restoration of epithelial thinning and atrophy of endometrial glands. The other treated groups show either minimal or no protection against bilateral ovariectomy-induced changes (Fig. 5).

\section{Discussion}

According to the National Medicinal Plant Board, Ministry of AYUSH, Government of India, New Delhi, domestic demand of Asoka bark is more than 100 metric tons per year. The available cultivation never fulfilled the commercial demands earlier nor can they do so in near future. The plant is red listed in vulnerable category and is reported to be endangered. Identification of a scientifically validated substitute for the bark of Saraca asoca is an urgent need of Ayurvedic industry $[16,17]$. The purpose of this study was to identify a scientifically validated alternative source for Asoka.

The bark of S. asoca is a rich source for many polyphenolic components. The estimation of major phenolics such as total phenolics, total flavonoids, and total catechins were estimated spectrophotometrically by various methods. The phenolic profiling of selected barks showed that S. asoca and T. orientalis contain higher amount of polyphenolics and it is in agreement with the previous reports $[18,19]$. The bark of Shorea robusta also showed comparatively higher phenolic content. Variation was also noticed with respect to the nature of the solvent used for extraction. The highest values were observed for hydroalcoholic extracts and this might be due to the optimum polarity of the alcohol-water combination for extracting maximum phenolic compounds [20].

Catechin estimation showed that the bark of S. asoca contains the highest catechins compared all other barks. It was also noticed that the catechin content of the stem of $S$. asoca is very low. Catechins are naturally occurring flavonols and well-demonstrated phytochemicals having a 


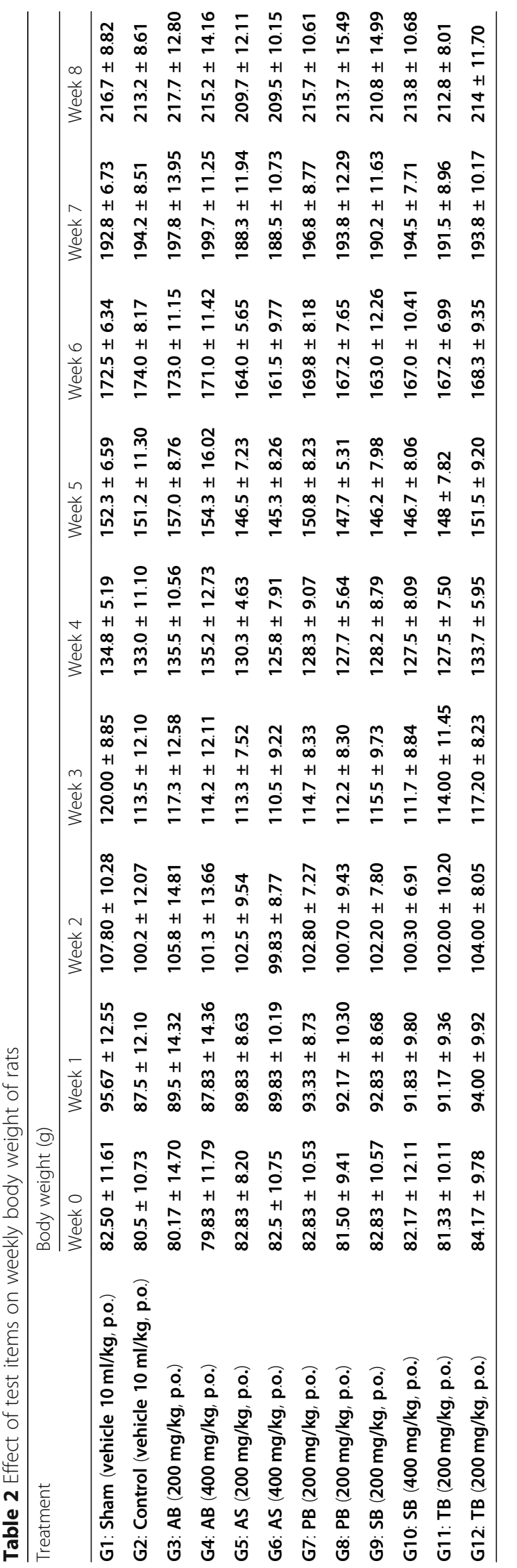


Table 3 Effect of test items on uterus weight, on uterine glycogen levels, and on serum lipid profile

\begin{tabular}{|c|c|c|c|c|c|}
\hline \multirow[t]{2}{*}{ Treatment } & \multirow{2}{*}{$\begin{array}{l}\text { Organ weights (g) } \\
\text { Uterus }\end{array}$} & \multirow{2}{*}{$\begin{array}{l}\text { Uterine glycogen } \\
\text { level }(\% \mathrm{w} / \mathrm{w})\end{array}$} & \multicolumn{3}{|l|}{$\underline{\text { Lipid profile }}$} \\
\hline & & & Total cholesterol (mg/dl) & Triglycerides (mg/dl) & $\mathrm{HDL}(\mathrm{mg} / \mathrm{dl})$ \\
\hline G1: Normal & $0.91 \pm 0.33$ & $0.52 \pm 0.11$ & $100.20 \pm 10.38$ & $81.67 \pm 7.94$ & $44.67 \pm 8.95$ \\
\hline G2: Control & $0.34 \pm 0.05^{\#}$ & $0.38 \pm 0.05^{\#}$ & $156.50 \pm 11.15^{\#}$ & $121.20 \pm 18.06^{\#}$ & $25.50 \pm 5.61^{\#}$ \\
\hline G3: AB (200 mg/kg, p.o.) & $0.80 \pm 0.20^{*}$ & $0.45 \pm 0.08$ & $136.50 \pm 12.65$ & $84.50 \pm 14.79^{*}$ & $35.17 \pm 3.86$ \\
\hline G4:AB (400 mg/kg, p.o.) & $1.02 \pm 0.14^{*}$ & $0.50 \pm 0.09$ & $98.83 \pm 14.08^{*}$ & $79.17 \pm 11.00^{*}$ & $44.50 \pm 7.23^{*}$ \\
\hline G5: AS (200 mg/kg, p.o.) & $0.36 \pm 0.08$ & $0.26 \pm 0.05$ & $143.30 \pm 14.18$ & $111.70 \pm 8.40$ & $28.17 \pm 5.84$ \\
\hline G6: AS (400 mg/kg, p.o.) & $0.99 \pm 0.11^{*}$ & $0.29 \pm 0.06$ & $109.20 \pm 13.18^{*}$ & $101.30 \pm 9.15^{*}$ & $41.67 \pm 6.71^{*}$ \\
\hline G7: PB (200 mg/kg, p.o.) & $0.44 \pm 0.14$ & $0.36 \pm 0.06$ & $151.00 \pm 16.67$ & $106.00 \pm 8.02$ & $26.00 \pm 8.36$ \\
\hline G8: PB (200 mg/kg, p.o.) & $0.53 \pm 0.14$ & $0.32 \pm 0.04$ & $137.70 \pm 14.62$ & $106.50 \pm 13.55$ & $25.50 \pm 5.54$ \\
\hline G9: SB (200 mg/kg, p.o.) & $0.83 \pm 0.17^{*}$ & $0.30 \pm 0.09$ & $113.20 \pm 18.12^{*}$ & $92.83 \pm 10.80^{*}$ & $36.83 \pm 6.73$ \\
\hline G10: SB (400 mg/kg, p.o.) & $1.00 \pm 0.09^{*}$ & $0.32 \pm 0.06$ & $102.70 \pm 14.61^{*}$ & $82.17 \pm 8.65^{*}$ & $40.50 \pm 9.00^{*}$ \\
\hline G11: TB (200 mg/kg, p.o.) & $0.47 \pm 0.12$ & $0.32 \pm 0.07$ & $149.20 \pm 10.57$ & $104.80 \pm 10.25$ & $28.67 \pm 10.27$ \\
\hline G12: TB (200 mg/kg, p.o.) & $0.59 \pm 0.12$ & $0.34 \pm 0.05$ & $153.00 \pm 8.19$ & $107.00 \pm 10.35$ & $25.00 \pm 6.54$ \\
\hline
\end{tabular}

Values are mean $\pm \mathrm{SD}, n=6,{ }^{\#} p<0.05$ when compared to GP1 normal and ${ }^{*} p<0.05$ when compared to GP-2 control by ANOVA followed by Dunnett's post-test

variety of pharmacological properties [8]. Specific catechins from various barks used were also identified by tandem mass spectroscopic analysis. LC/MS analysis showed that catechins such as Catechin, Epicatechin, Epicatechin3 gallate, Gallo catechin, and Gallocatechin-3-gallate were found to be present in barks of both S. asoca and S. robusta. Estrogenic activity of catechins and isoflavones are well established [21, 22].

In Ayurveda, Asoka is primarily used for the management of female reproductive problems. The estrogenic activity of Asoka was evaluated in comparison with other selected bark drugs. The study concluded that both $S$. asoca and $S$. robusta showed significant estrogenic activity in experimental animals.

\section{Conclusion}

Phytochemical and pharmacological evaluation has been carried out using plant parts of four medicinal plants viz, S. asoca, P. longifolia, S. robusta and $T$. orientalis to find out the substitute for Asoka. On the basis of overall evaluation, the possibility of using bark of Shorea robusta as a substitute for Asoka is suggested for further studies. The present study also revealed that the bark of $P$. longifolia which is the common adulterant in the trading of Asoka bark has entirely different chemical and biological properties and hence the adulteration of Asoka with $P$. longifolia will adversely affect the quality of finished formulations.

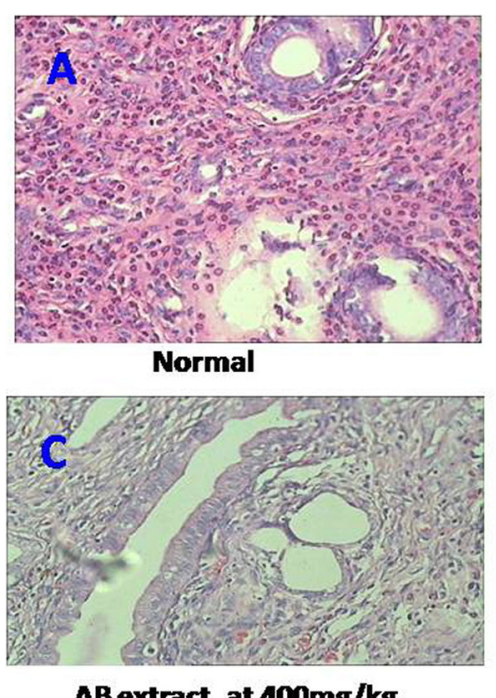

AB extract at $400 \mathrm{mg} / \mathbf{k g}$

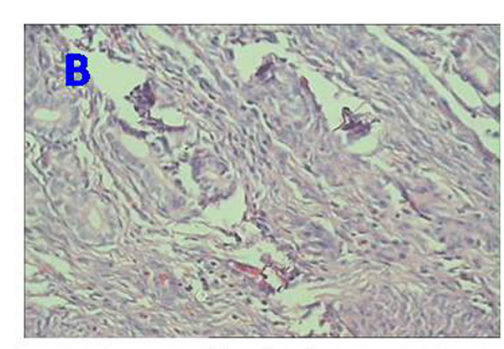

Control

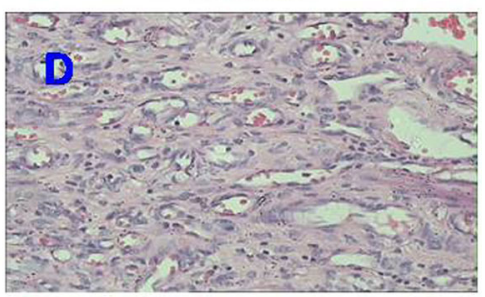

SB extract at $400 \mathrm{mg} / \mathrm{kg}$

Fig. 5 Histopathology of the uterus of the normal, control, and treated group 


\section{Abbreviations}

AB: Saraca asoca bark; AS: Saraca asoca stem; PB: Polyalthia longifolia bark; SB: Shorea robusta bark; TB: Trema orientalis bark; LC-MS/MS: Liquid chromatography mass spectroscopy; HPTLC: High-performance thin-layer chromatography

\section{Acknowledgements}

The authors are thankful to Dr. T K Praveen, Department of Pharmacology, JSS College of Pharmacy, Ooty, Tamil Nadu, India, for his support in Pharmacological studies. The authors are thankful to the National Medicinal Plants Board, Ministry of AYUSH, Government of India, for financial assistance (Project \# R\&D/KE-01/2015-16)

\section{Details of plant sources}

Saraca asoca (Roxb.) Wild: Herb garden, Arya Vaidya Sala, Kottakkal, Kerala, India (Voucher specimen No: CMPR 11252)

Polyalthia longifolia (Sonn.) Thwaites: Herb garden, Arya Vaidya Sala, Kottakkal, Kerala, India (Voucher specimen No: CMPR 11253) Shorea robusta Gaertn: Chattisgarh: (Voucher specimen No: CMPR 11255) Trema orientalis (L.) Blume: Herb garden, Arya Vaidya Sala, Kottakkal, Kerala, India (Voucher specimen No: CMPR 11251)

\section{Authors' contributions}

All authors have read and approved the manuscript. SCT designed and executed the work, LC/MS analysis, and pharmacological evaluation and drafted the manuscript. JCK participated in extraction, HPTLC analysis, and estimations. JKU participated in extraction, HPTLC analysis, and estimations. PKM collected the plant materials. IB participated in planning and edited the manuscript.

\section{Funding}

The entire work was financially supported by National Medicinal Plants Board (NMPB), Ministry of AYUSH, Government of India (grant number R\&D KE-01/2015-16)

\section{Availability of data and materials}

All data and material are available upon request.

\section{Ethics approval and consent to participate}

The experimental procedures relating to the animals were authorized by Committee for the Purpose of Control and Supervision of Experiments on Animals (CPCSEA) (approval no. JSSCP/IAEC/OT/Ph.D/Ph.Cology/05/2017-18)

\section{Consent for publication}

Not applicable

\section{Competing interests}

The authors declare that they have no competing interests.

Received: 13 December 2019 Accepted: 25 February 2020

\section{0.00}

\section{References}

1. Sivarajan W, Balachandran I (1994) Ayurvedic drugs and their plant sources. Oxford \& IBH Publishing Co. Pvt. LTD, New Delhi, pp 57-59

2. Udayan PS, Balachandran I (2009) Medicinal Plants of Arya Vaidya Sala Herb garden. Arya Vaidya Sala Kottakkal 529

3. Rathee P, Rathee S, Rathee D, Rathee D, Kalia AN (2010) In vitro antioxidant studies and total phenolic content of Ficus religiosa fruits extract. Pharmacologyonline 2:737-737

4. Warrier PK, Nambiar VPK, Ramankutty C (1996) Indian medicinal plants: a compendium of 500 species, vol 5, p 592

5. Begum SN, Ravikumar K, Ved DK (2014) Asoka' - an important medicinal plant, its market scenario and conservation measures in India. Curr Sci 107 26-28

6. Singleton VL, Rossi JA Jr (1965) Colorimetry of total phenolics with phosphomolybdic phosphotungstic acid reagents. Am J Eno Viticulture 16: 144-158

7. Sulaiman CT, Thushar KV, George S, Balachandran I (2014) Phenolic characterization of selected Salacia species using LC-ESI-MS/MS analysis. Nat Prod Res 28:1021-1024
8. Singh HP, Ravindranath SD, Singh C (1999) Analysis of tea shoot catechins: spectrophotometric quantitation and selective visualization on twodimensional paper chromatograms using diazotized sulfanilamide. J Agric Food Chem 47:1041-1045

9. Pariyani R, Ismail IS, Azam AA, Abas F, Shaari K, Sulaiman MR. (2015) Phytochemical screening and acute oral toxicity study of java tea leaf extracts. BioMed Research International. https://doi.org/10.1155/2015/742420.

10. Vijayanarayana K, Rodrigues RS, Chandrashekhar KS, Subrahmanyam EV (2007) Evaluation of estrogenic activity of alcoholic extract of rhizomes of Curculigo orchioides. J Ethnopharmacol 1:241-245

11. Sulaiman CT, Balachandran I (2016) LC/MS characterization of phenolic antioxidants of Brindle berry (Garcinia gummi-gutta (L.) Robson). Natural Product Res 31:1191-1194

12. Sulaiman CT, Arun A, Anandan EM, Sandhya CR, Balachandran I (2015) Isolation and identification of phytoestrogens and flavonoids in an Ayurvedic proprietary medicine using chromatographic and mass spectroscopic analysis. Asian Pac J Reprod. 4:153-156

13. Mena P, Cirlini M, Tassotti M, Herrlinger KA, Asta CD, Rio DD (2016) Phytochemical profiling of flavonoids, phenolic acids, terpenoids, and volatile fraction of a rosemary (Rosmarinus officinalis L.) extract. Molecules. 21:1576

14. Sulaiman CT, Balachandran I (2016) LC/MS characterization of antioxidant flavonoids from Tragia involucrata L. Beni-Suef University. J Basic Appl Sci 5: 231-235

15. Lakmichi H, Bakhtaoui FZ, Gadhi CA, Ezoubeiri A, Jahiri YE, Mansouri AE, Zrara I, Loutfi K (2011) Evidence-based complementary and alternative medicine. https://doi.org/10.1155/2011/317090

16. Singh S, Krishna TH, Kamalraj S, Kuriakose GC, Valayil JM, Jayabaskaran C (2015) Phytomedicinal importance of Saraca asoca (Ashoka): an exciting past, an emerging present and a promising future. Curr Sci. 109:1790-1801

17. Senapati SK, Das GK, Aparajita S, Rout GR (2012) Assessment of genetic variability in the Asoka tree of India. Biodiversity. 13:16-23

18. Wen-Lung K, Yu-Ling H, Shr-Ting W, Ching-Li N, Bor-Jinn S, Chien-Chih C (2007) Chemical constituents of Trema orientalis. J Chin Med 18:27-36

19. Sulaiman CT, Balachandran I (2012) Total phenolics and total flavonoids in selected Indian medicinal plants. Indian J Pharm Sci.: 74; 258-260.

20. Kowalczyk D, Świeca M, Cichocka J, Gawlik-Dziki U (2013) The phenolic content and antioxidant activity of the aqueous and hydroalcoholic extracts of hops and their pellets. J Inst Brew. 119:103-110

21. Kuruto-Niwa R, Inoue S, Ogawa S, Muramatsu M, Nozawa R (2000) Effects of tea catechins on the ERE-regulated estrogenic activity. J Agric Food Chem. 48:6355-6361

22. Breinholt V, Hossaini A, Svendsen GW, Brouwer C, Nielsen E (2000) Estrogenic activity of flavonoids in mice. The importance of estrogen receptor distribution, metabolism and bioavailability. Food Chem Toxicol. 38:555-564

\section{Publisher's Note}

Springer Nature remains neutral with regard to jurisdictional claims in published maps and institutional affiliations.

\section{Submit your manuscript to a SpringerOpen ${ }^{\bullet}$ journal and benefit from:}

- Convenient online submission

- Rigorous peer review

- Open access: articles freely available online

- High visibility within the field

- Retaining the copyright to your article

Submit your next manuscript at $>$ springeropen.com 